\title{
Auditoria interna: contextualização teórica e aplicações em empresas comerciais brasileiras
}

A auditoria surgiu com a necessidade de emitir um parecer acerca de opinar se os relatórios apresentados estavam de acordo com a realidade da empresa, transmitindo assim para a sociedade a confiabilidade das informações. Portanto, define-se a auditoria como técnica que confere, verifica e avalia documentos e registros, inspeções, obtenção de informações, com a finalidade de verificar se as demonstrações contábeis condizem com a realidade constatada. A auditoria é uma área vinculada à administração onde promove a verificação dos controles internos, podendo assim verificar a sua eficiência e eficácia, reduzindo as chances de erros e fraudes. Na auditoria independente devem ser formalmente documentados e preparados o planejamento, procedimentos que serão aplicados e os programas de trabalho que devem servir como guia e controle na execução do trabalho. O seu objetivo é opinar através de um parecer acerca da fidedignidade das demonstrações contábeis e apresentar a quem for de responsabilidade para fazer ou não as devidas correções e auxiliar na tomada de decisões. Nos papéis de trabalho são anexadas análises, demonstrações ou quaisquer outros documentos onde devem ser analisadas e verificadas, para demonstrar ao leitor com facilidade como foram realizados os procedimentos e as conclusões obtidas. Algumas empresas são obrigadas legalmente a contratar uma auditoria interna, já outras contratam uma auditoria por medida de controle interno tomada por acionista, empresário, administrador da empresa e etc., ou por exigências estatutária ou contratual e para fins de consolidação das demonstrações contábeis.

Palavras-chave: Auditoria; Controle; Demonstrações; Verificação.

\section{Internal audit: theoretical context and applications in Brazilian commercial companies}

\begin{abstract}
The audit arose with the need to issue an opinion on whether the reports presented were in accordance with the reality of the company, thus transmitting to society the reliability of the information. Therefore, the audit is defined as a technique that checks, verifies and evaluates documents and records, inspections, obtaining information, with the purpose of verifying whether the financial statements are consistent with the verified reality. Auditing is an area linked to management where it promotes the verification of internal controls, thus being able to verify its efficiency and effectiveness, reducing the chances of errors and fraud. In the independent audit, the planning, procedures to be applied and the work programs that should serve as a guide and control in the execution of the work must be formally documented and prepared. Its objective is to express an opinion through an opinion on the reliability of the financial statements and to present to anyone who is responsible for making or not making the necessary corrections and assisting in decision making. Analyzes, demonstrations or any other documents are attached to the working papers, where they must be analyzed and verified, in order to easily demonstrate to the reader how the procedures and conclusions obtained were carried out. Some companies are legally required to contract an internal audit, while others contract an audit by internal control measure taken by a shareholder, entrepreneur, company administrator, etc., or by statutory or contractual requirements and for the purpose of consolidating the financial statements.
\end{abstract}

Keywords: Audit; Control; Demonstrations; Verification.

Topic: Finanças Empresariais

Reviewed anonymously in the process of blind peer.
Received: $20 / 03 / 2020$

Approved: 04/04/2020
Elaine Pinheiro Simões (10)

Faculdade Integradas de Sergipe, Brasil http://lattes.cnpq.br/8745049819040168

http://orcid.org/0000-0002-5981-1639

elaine psimoes@yahoo.com.br

Alvani Bomfim de Sousa Júnior (D)

Faculdade Jardins, Brasil

http://lattes.cnpq.br/6358502728889050

http://orcid.org/0000-0002-8714-4175

alvanijunior@yahoo.com.br
Referencing this:

SIMÕES, E. P.; SOUSA JÚNIOR, A. B.. Auditoria interna: contextualização teórica e aplicações em empresas comerciais brasileiras. Entrepreneurship, v.4, n.2, p.13-24, 2020. DOI: http://doi.org/10.6008/CBPC2595-4318.2020.002.0002 


\section{INTRODUÇÃO}

A auditoria é considerada por alguns administradores como custos, mas na verdade é um investimento que traz inúmeros benefícios, através da veracidade das informações. Segundo Rosário (2010), "as empresas necessitam cada vez mais de informações para servir de alicerce na sua tomada de decisão. No entanto se aquelas não são fidedignas e confiáveis, as decisões ficam comprometidas". Ou seja, a auditoria surgiu com a necessidade de emitir um parecer para opinar se os relatórios apresentados estavam de acordo com a realidade da empresa, transmitindo assim para a sociedade a confiabilidade das informações e contribuindo com a organização para alcançar seus objetivos, como expansão no mercado e no patrimônio, através de empréstimos e investidores. $O$ auditor interno tem o papel de apontar erros e distorções para possíveis correções, antes de ser examinado por um auditor externo e o mesmo emitir um relatório que tenha como resultado, divergências no que condiz com a realidade da empresa. Portanto, o presente trabalho tem como objetivo demonstrar como é aplicada a auditoria interna em empresas comerciais brasileiras, especificamente: evidenciar a auditoria interna; explicar os papeis de trabalho e demonstrar como é aplicada a auditoria interna na organização.

Com a sociedade exigente, mais fraudes acontecendo e o mercado bastante competitivo, é necessário pessoas competentes e um sistema de controle mais rígido, que acompanhe continuamente as mudanças da empresa. Sendo assim, com a aplicabilidade da auditoria interna o que se pode obter e quais resultados as organizações podem atingir?. A proposta deste trabalho é de suma importância para os administradores de empresas que queiram implantar a auditoria interna, por entender que com a sua implantação se possibilite o gerenciamento de risco e maior confiabilidade das informações geradas. Poderá ser explorado também como auxílio para estudantes, pesquisadores e contadores que querem saber mais sobre a área de auditoria. Este trabalho se encontra dividido nas seguintes seções: além desta introdução, segue a fundamentação teórica sobre auditoria interna: um enfoque teórico de sua aplicação em empresas comerciais brasileiras; na terceira seção estão descritas as hipóteses, na quarta a descrição dos procedimentos metodológicos, na quinta seção a análise dos principais resultados e, finalmente, são expostas na sexta seção as considerações finais.

\section{REVISÃO TEÓRICA}

\section{Evidenciar a auditoria interna}

Segundo Pinho (2007) entende que:

[...] o berço da auditoria na sua concepção moderna foi a Inglaterra no século XIII, atribuindo a Eduardo I, o uso do termo pela primeira vez.... Ele próprio mandou verificar as contas do testamento de sua falecida esposa. A aprovação desses autores é atestada em um documento que constitui um dos primeiros relatórios de auditoria, denominado "probatur" sobre as contas.

Porém, foi após a crise econômica americana de 1929 que a auditoria teve impulso. Com a finalidade de estabelecer regras para as empresas S.A. (Sociedade Anônima), tornando obrigatória a auditoria, foi criada, no início dos anos 30, o Comitê May. No Brasil, a auditoria se iniciou na década de 40 com a chegada 
das multinacionais. A lei 4.728 de 14 de julho de 1965 é a primeira lei do mercado de capitais, em que há explicações sobre a evolução do mercado, prática e sobre sua obrigatoriedade. A partir dessa lei a sociedade obteve-se mais confiabilidade nas informações que eram transmitidas. Na década de 60 surgiu o Instituto dos Contadores Públicos do Brasil, que em 1971 se transformou no atual Instituto dos Auditores Independentes do Brasil (IBRACON).

Gomes et al. (2009) conceituam a auditoria como

Uma verificação das transações, operações e procedimentos efetuados por uma entidade onde são examinados documentos, livros, registros, demonstrações e de quaisquer elementos de consideração contábil, objetivando a veracidade desses registros e das demonstrações contábeis deles decorrentes e visando a apresentação de opiniões, críticas, conclusões e orientações.

Já para Rivera (1955, citado por SANTOS et al., 2014), "auditoria é o exame de todas as anotações contábeis, a fim de comprovar sua exatidão, assim como a veracidade dos estados ou situações que as ditas anotações produzem". Logo, define-se a auditoria como técnica que confere, verifica e avalia documentos e registros, inspeções, obtenção de informações externas e internas, com a finalidade de verificar se as demonstrações contábeis condizem com a realidade constatada e se está de acordo com as normas e princípios fundamentais de contabilidade. A auditoria tem papel fundamental em uma organização porque é através do parecer de um auditor que os stakeholders (público, uma pessoa ou grupo que possui interesse pela empresa) poderão ter a certeza se a organização é digna ao informar os atos e fatos que nela ocorrem.

A auditoria é dividida em auditoria externa ou independente e auditoria interna, esta última é uma prevenção de fraudes e erros, podendo ser corrigida antes de uma avaliação da auditoria externa.

O auditor externo passava muito tempo direcionado para o exame das demonstrações contábeis, no entanto para atender a administração era necessária uma auditoria mais detalhada relacionada as outras áreas da contabilidade (controle interno, parte financeira, gerencial, etc.), com isso surgiu o auditor interno, que serve como um aparato para o auditor externo e o contador.

Marçola (2011) afirma que a "auditoria interna verifica e testa os controles internos, em todas as áreas da organização". Portanto, a auditoria interna não se confunde com controle interno, a auditoria é uma área vinculada à administração onde se promove a verificação dos controles internos que se refere a procedimentos, métodos ou rotinas de organização de todos os setores da instituição.

Segundo Franco et al. (2001, citado por TRISCIUZZI, 2009), entende-se por controle interno "todos os instrumentos contábeis da organização destinados à vigilância, e fiscalização, que permitam prever, observar, dirigir ou governar os acontecimentos que se verificam dentro da empresa e que produzam reflexos em seu patrimônio".

Segundo Lima et al. (2003, citado por MARÇOLA, 2011), "a auditoria atua auxiliando o administrador na tomada de decisões, por meio de relatórios e pareceres, bem como colabora para a evidenciação de erro, omissão ou fraude". Com a expansão das organizações no mercado, os administradores necessitam do auxílio da auditoria interna para obter informações corretas da situação patrimonial e financeira da empresa, para saber sobre a sua posição no mercado e abrir seu capital para novos investidores. Para isso a auditoria interna tem que ser executada por um funcionário qualificado, da própria empresa, para área com o objetivo de 
detectar falhas, garantir a salvaguarda dos ativos da empresa e manter o controle contábil.

O objetivo da auditoria externa é opinar, através de um parecer acerca da fidedignidade das demonstrações contábeis, ou seja, se estas estão de acordo com princípios e normas fundamentais da contabilidade. Sendo assim, a auditoria interna serve para prevenção de erros ou fraudes das demonstrações antes mesmo de uma auditoria externa e para isso tem que ser verificada sempre que houver necessidade.

\section{Explicar os papéis de trabalho}

O auditor interno deve apresentar um relatório a quem tenha solicitado o trabalho ou a quem este autorizar, sendo confidencial seu conteúdo, este documento deve ser elaborado com objetividade, imparcialidade e clareza, ou seja, conforme a necessidade se pode avaliar a emissão de um relatório parcial, caso seja detectado impropriedades, irregularidades e/ou ilegalidades que necessitem providências imediatas.

De acordo com as Normas Brasileiras de Contabilidade de Auditoria Interna - NBC TI 01, 12.3.2:

O relatório da Auditoria Interna deve abordar, no mínimo, os seguintes aspectos: a) o objetivo e a extensão dos trabalhos; b) a metodologia adotada; c) os principais procedimentos de auditoria aplicados e sua extensão; d) eventuais limitações ao alcance dos procedimentos de auditoria; e) a descrição dos fatos constatados e as evidências encontradas; f) os riscos associados aos fatos constatados; e g) as conclusões e as recomendações resultantes dos fatos constatados. (CFC, 2012)

Segundo a NBC TI 01, 12.2.1.1 o planejamento do trabalho da Auditoria Interna compreende os exames preliminares das áreas, atividades, produtos e processos, para definir a amplitude e a época do trabalho a ser realizado, de acordo com as diretrizes estabelecidas pela administração da entidade. Desta forma, para a realização dos procedimentos de auditoria é necessário entender como funciona a organização, ou seja, considerar alguns fatores relevantes como o conhecimento detalhado: da política, missão, visão e objetivos estratégicos da entidade; gestão de risco da organização; atividades operacionais; sistemas contábil; controles internos e seu grau de confiabilidade; existência de entidades associadas, filiais e partes relacionadas no âmbito dos trabalhos da auditoria interna; resultado e providências tomadas em relação a trabalhos anteriores da auditoria e orientações e expectativas da administração aos auditores internos.

$\mathrm{Na}$ auditoria interna devem ser formalmente documentados e preparados o planejamento, procedimentos que serão aplicados e os programas de trabalho que devem servir como guia e controle na execução do trabalho, porém devem ser atualizados e revisados quando necessário.

Os procedimentos da Auditoria Interna constituem exames e investigações, incluindo testes de observância e testes substantivos, que permitem ao auditor interno obter subsídios suficientes para fundamentar suas conclusões e recomendações à administração da entidade, de acordo com as Normas Brasileiras de Contabilidade - NBC TI 01, 12.2.3.1. (CFC, 2012)

Os testes de observância visam obter segurança, a saber se os controles internos estão funcionando como o esperado, para isso devem ser considerados os procedimentos de inspeção, observação e investigação e confirmação. Já os testes substantivos visam a obter evidências produzidas pelos sistemas de informação da organização, quanto à suficiência, exatidão e validade dos dados. 
Os papéis de trabalho são elaborados em meio físico ou eletrônico e devem ser organizados e arquivados de forma sistemática e racional, onde são constituídos por documentos e registros dos fatos, informações e provas, obtido através dos exames realizados, com objetivo de dar suporte à opinião, críticas, sugestões e recomendações do auditor, junto a esses papéis são anexadas análises, demonstrações ou quaisquer outros documentos onde devem ser analisadas e verificadas.

De acordo com as NBC TI 01, 12.1.2.3:

Os papéis de trabalho devem ter abrangência e grau de detalhe suficientes para propiciarem a compreensão do planejamento, da natureza, da oportunidade e da extensão dos procedimentos de Auditoria Interna aplicados, bem como do julgamento exercido e do suporte das conclusões alcançadas. (CFC, 2012)

Isso é necessário para quem for ter acesso a esses papéis a fim de compreender com facilidade como foram realizados os procedimentos e as conclusões obtidas, o que gera uma transparência para o leitor dos documentos. Segundo Lins (2012) diz:

O relatório final é o documento pelo qual a auditoria interna apresenta o resultado dos seus trabalhos, devendo ser redigido com objetividade e imparcialidade, de forma a expressar, claramente, suas conclusões, recomendações e providências a serem tomadas pela administração da entidade.

Ou seja, após a obtenção das evidências da auditoria interna é necessário tomar algumas providências para a prevenção de um relatório de parecer não desejado. O relatório final de uma auditoria bem-sucedida, interessa principalmente aos executivos da empresa, financiadores, fornecedores, fisco, investidores, poder público, clientes e funcionários, ou seja, os stakeholders.

\section{Demonstrar como é aplicada a auditoria interna na organização}

A auditoria surgiu e progrediu em consequência do crescimento de empresas, novos entrantes no mercado, financiamentos e empréstimos, controle por parte do poder público, exportação, vendas de ações, imposto de renda e a preocupação dos clientes e funcionários com a transparência das informações fornecidas.

São obrigadas a contratar uma auditoria independente as empresas com ações na bolsa de valores e empresas de capital fechado de grande porte que detenham um ativo total superior a $\mathrm{R} \$ 240.000 .000,00$ ou receita bruta anual superior a $\mathrm{R} \$ 300.000 .000,00$ de acordo com a lei 11.638/07 (Lei das Sociedades por Ações). Além de serem obrigadas legalmente, as organizações contratam uma auditoria por medida de controle interno tomada por acionista, empresário, administrador da empresa e etc., por exigência estatutária ou contratual, aquisição, fusão, cisão, incorporação da empresa e para fins de consolidação das demonstrações contábeis. Já a auditoria interna é facultativa a sua contratação, exceto para as empresas estatais e para verificar o sistema de gestão da qualidade antes da certificação ou realizada também por medida de autocontrole. Para a realização dos procedimentos a auditoria externa é realizada por um profissional contratado pela empresa e a auditoria interna é realizado por um empregado interno.

Segundo Lins (2012), “a diferença da auditoria interna realizada por funcionários da empresa e terceiros diz respeito ao tempo. A auditoria realizada por funcionários é contínua, e a feita por terceiros é 
pontual e com prazo determinado".

Já a auditoria interna para Pinheiro et al. (2003) que:

É executada por funcionários da empresa de forma permanente e com absoluta independência, cujo objetivo principal é atender à administração da empresa na implementação e vigilância nas normas internas definidas, avaliando e aperfeiçoando com sugestões o controle interno.

Porém, para exercer essa função, o funcionário deve ser capacitado, ter conhecimento na área, ter alto grau de confiança por parte dos administradores e conhecer as normas internas da organização.

Segundo Pinheiro et al. (2003), "o auditor interno ao realizar a auditoria das contas pública ou a auditoria financeira e orçamentária tem como finalidade principal, o exame e o julgamento da legalidade das contas e das gestões administrativas". O auditor interno tem como finalidade apontar erros e fraudes para possíveis correções para uma auditoria independente, principalmente, quando se tratarem de contas públicas, pois estas têm um maior grau de repercussão na mídia, por isso é necessário ser realizada por um bom profissional. É importante também manter o foco em uma auditoria financeira em consequência de fraudes que podem levar uma empresa à falência.

De acordo com pesquisas realizadas anualmente pela Kroll, em conjunto com a Economist Intelligence Unit (citado por CORDEIRO, 2011), o Brasil é o terceiro país em que as empresas mais registram casos de perdas em decorrência de fraudes.

Prado (2010) afirma que "o termo 'fraude' aplica-se a ato intencional de omissão e/ou manipulação de transações e operações, adulteração de documentos, registros, relatórios, informações e demonstrações contábeis, tanto em termos físicos quanto monetários". Nas organizações as fraudes geralmente são cometidas por pessoas ligadas a administração, porém quando as organizações são de grande porte, a identificação habitualmente é despercebida e demorada, pelo tamanho do capital, quantidade de funcionários e pela estrutura organizacional. Já o termo "erro", Prado (2010) acredita que "aplica-se a ato não intencional de omissão, desatenção, desconhecimento ou má interpretação de fatos na elaboração de registros, informações e demonstrações contábeis, bem como de transações e operações da entidade, tanto em termos físicos quanto monetários". O erro mesmo não sendo de intenção do funcionário, cabe a ele a responsabilidade de corrigir e responder pelos seus atos, porém quem paga legalmente é a empresa.

De acordo com a tipologia dos enfoques a serem identificados para detecção de fraudes apresentadas por Gil (1999, citado por PINHEIRO et al., 2003) a análise deve ser:

Sistêmica - com conhecimento detalhado do modelo organizacional e sua respectiva tecnologia de controles e particularmente seu ambiente e sua plataforma de informática.

Quantitativa - deve antever a existência de fraudes e propor atuação com análise de risco, indicadores de qualidade operacional e da segurança, estatísticas, erros intencionais/ não intencionais, gráficos de tendências de fraudes, dimensionamento de sinais exteriores de riqueza, parâmetros que necessariamente devem utilizar a informática para a quantificação.

Comportamental - Os dados de pesquisa são consensuais em identificar que a maioria das ações fraudulentas são de origem interna, ou seja, são arquitetadas por profissionais que integram o quadro de funcionários e colaboradores da empresa. Neste aspecto torna-se fundamental o papel dos recursos humanos para verificação de antecedentes (Background checks), inclusive em relação a fornecedores, prestadores de serviço, terceirizados, 
investidores, etc. Um grande número de fraudes ocorre com funcionários que detêm algum grau de confiança. A pesquisa da KPMG (2000) demonstra que $50 \%$ dos envolvidos na fraude ocupam posição de gerência e ou supervisão e $49 \%$ pessoal de suporte.

Os administradores das empresas têm que se antever ao comportamento dos empregados, muitas vezes os fraudadores mudam seus comportamentos, se interessam pelos dados e informações detalhadas da empresa sem ao menos ser sua área de atuação, bajulam e prestam serviço em excesso, e dão palpites nas fraquezas dos controles, para se conquistar um grau de confiança.

Cordeiro (2011) evidencia que "vários são os fatores que favorecem as fraudes, como a perda dos valores éticos e morais, necessidade de ostentação de riqueza, negligência nos controles internos, oportunidade pela falta de controles, entre muitos outros".

Tem pessoas que entram na empresa e querem crescer junto com ela, já outras pessoas querem crescer em cima da empresa, ocasionando a fraude e vindo assim a prejudicar a empresa, tanto na redução de seus bens, como também na falta de confiança dos stakeholders. Portanto, se a empresa quer conquistar a confiança de seus investidores, fornecedores, clientes, do fisco, da sociedade, obter empréstimos, maior visibilidade no mercado, expansão, estrutura organizacional, maior segurança nas demonstrações e reduzir suas distorções, é importante ter um sistema eficiente e eficaz e um funcionário capacitado para exercer o controle interno e garantir a veracidade das informações transmitidas.

\section{Hipótese}

O presente trabalho demonstra que a aplicabilidade de uma auditoria eficaz, bem como a utilização de controles internos, pode ser considerada como fatores fundamentais para a redução de erros e fraudes, como também inúmeras vantagens comerciais e financeiras. Portanto, através de sua aplicação as organizações têm como possíveis resultados as seguintes hipóteses, definidas a partir de debates exploratórios entre os autores e pesquisadores interessados no tema: A auditoria interna auxilia a organização a reduzir os seus custos, através do controle interno e de um bom profissional; Com um forte sistema contábil de controles eficientes, transmite-se maior segurança nos números apresentados, trazendo assim confiabilidade para os investidores; Com a auditoria interna, a conferência, verificação e análise das informações transmitidas desestimulam fraudes e distorções.

\section{METODOLOGIA}

Segundo Silva (2010), "a metodologia relaciona-se com os objetivos e a finalidade do projeto. Deve descrever os passos dados para alcançar os objetivos". Dessa forma, para alcançar o objetivo deste trabalho foi utilizado o levantamento documental, que através desse instrumento qualquer informação coletada sob diversas formas, devem ser levadas em consideração de acordo com cada objetivo de estudo. Foi utilizado também pesquisas em livros, artigos existentes sobre o assunto e a análise de dados que tenta explicar a relação entre a teoria e a prática. 


\section{RESULTADOS E DISCUSSÃO}

Nesta seção serão discutidos os resultados e discussões apurados durante a pesquisa, através de diversos trabalhos existentes acerca do assunto, onde foram levantadas possíveis respostas para a situação problema. Este trabalho buscou demonstrar como é aplicado a auditoria interna em empresas comerciais brasileiras, diante disso foram elaboradas três hipóteses, com intuito de encontrar respostas para a problemática apresentada. A primeira hipótese da pesquisa diz respeito à auditoria interna auxiliar a organização a reduzir os seus custos, através do controle interno e de um bom profissional.

Pinheiro (2013) realça que se durante o trabalho da auditoria forem detectados erros, devem-se sugerir recomendações para auxiliar na identificação de oportunidade e crescimento dos lucros. Pinheiro acredita que durante muitas décadas a auditoria interna visava apenas a fiabilidade dos controles internos, mas com o tempo surgiu a oportunidade de mudança, que foca nos riscos estratégicos do negócio e financeiro, além de trazer valor para o acionista, que alinha a estratégia à criação de valor nos processos e ao mesmo tempo torna as operações mais eficientes, ou seja, reduz os custos e ganhar a eficiência. 0 profissional da auditoria interna deve estar permanentemente atualizado, através de estudos contínuos, adequando-se e adaptando-se às novas exigências do mercado, permitindo assim acrescentar valor à organização.

Pereira (2012) enfatiza na sua obra que, durante o processo, a empresa ao utilizar os indicadores de risco pode aprimorar o seu desempenho, processos e o seu ambiente de trabalho, podendo trazer vários benefícios como reduzir as perdas, identificar as oportunidades para a exploração estratégica e reduzir custos de capital, entre outros. O conselho de administração deverá ter em conta os custos e os benefícios de acordo com os riscos e atividades de controle. A estrutura organizacional envolve os processos de planeamento, execução, controle e acompanhamento das atividades de uma entidade, que deve ser conciliável com as suas necessidades, permitindo a gestão de risco a alcançar os seus objetivos.

Na discussão dos autores conclui-se que a auditoria evoluiu e não foca apenas nos controles internos, mas também nos riscos operacionais, ou seja, além de reduzir o custo do risco traz também as vantagens, trazendo assim valor para a organização. A implementação de controles internos e a utilização da auditoria interna, podem ser utilizados como ferramentas de controle e redução dos custos. No relatório da execução das atividades, contém informações necessárias para a administração, mas caso sejam detectados erros se deve sugerir recomendações, promovendo uma melhora na gestão. O profissional da auditoria interna deve estar sempre atualizado, para resolver as diversas situações que surgirem e, assim, trazer valor para a organização. Na segunda hipótese da pesquisa, acredita-se que um forte sistema contábil de controles eficientes transmite maior segurança nos números apresentados, trazendo assim confiabilidade para os investidores.

Hames (2004) afirma que a auditoria interna tem como missão auxiliar a companhia a atingir os resultados esperados, focando na melhoria dos controles e processos, minimizando assim os riscos e possibilitando ao cliente interno, tranquilidade em relação aos controles que foram examinados. Para 
enfrentar desafios e tomarem a melhor decisão, as empresas devem manter um sistema de controle que envolva um processo de planejamento, de forma a garantir à gestão a integridade da organização.

A organização precisa se munir de relatórios e sistemas que sejam confiáveis e eficientes, garantindoIhes, a situação econômico financeira da instituição. $\mathrm{O}$ auditor deve efetuar o levantamento do sistema contábil e do controle interno da empresa, avaliar o grau de segurança e estabelecer a natureza, a extensão e a profundidade dos procedimentos de auditoria, assim como o momento apropriado de sua aplicação. $O$ sistema contábil e o controle interno são de responsabilidade da empresa. Entretanto, é recomendável que o auditor faça sugestões objetivas no sentido de eliminar as deficiências nele existentes no decurso de seus exames. Um bom sistema contábil de informação deve ser articulado de dados, ajustes e relatórios que permitam tratar as informações com o máximo possível de relevância que atendam às necessidades dos gestores da empresa e o mínimo de custos, porém é importante a geração de dados exatos para a sustentação do sistema de informações, assim como de sua credibilidade. Nesse aspecto, um controle interno adequado proporciona segurança que os relatórios contábeis e gerenciais são fidedignos e retratam de forma clara a realidade da empresa (BORDIN et al., 2005).

Segundo Lima et al. (2012) após o planejamento, elaboração e definição dos procedimentos, o controle é executado através do sistema contábil, sistema de comunicação e sistema de informação, em que serão transmitidas informações confiáveis e ciclos operacionais eficientes, fazendo com que as decisões se transformem em resultados positivos. Muitas empresas optam em contratar um auditor independente com a finalidade de analisar as demonstrações financeiras e emitir seu relatório, através de testes, provas e procedimentos utilizando as normas de auditoria, porém o mesmo fará um levantamento do sistema contábil e do controle interno, entendendo todo o processo, fazendo o planejamento da auditoria e caso o controle for deficiente o mesmo fará recomendações de aperfeiçoamento para assegurar a eficácia dos registros contábeis.

Através da pesquisa entende-se que para enfrentar desafios e tomarem a melhor decisão, as empresas devem manter um sistema contábil e de controle interno que sejam confiáveis e eficientes, garantindo-Ihes, a situação econômico financeira da instituição. Um bom sistema contábil de informação deve ser articulado de dados, ajustes e relatórios que permitam tratar as informações com o máximo possível de relevância que atendam às necessidades dos gestores da empresa e o mínimo de custos. Portanto, a auditoria interna tem como missão auxiliar a companhia a atingir os resultados esperados, focando na melhoria dos controles e processos, minimizando assim os riscos e possibilitando ao cliente interno, tranquilidade em relação aos controles que foram examinados. A última hipótese evidencia que, com a auditoria interna, a conferência, verificação, análise das informações transmitidas e a aplicabilidade de controle interno desestimulam fraudes e distorções.

Oliveira (2009) afirma que na auditoria interna, as revisões e os controles sobre os demais controles reduzem as possibilidades de fraudes, logo, a falta ou fraqueza desses controles é que facilita a ocorrência da fraude. As empresas se protegem realizando controles, mas precisam aferir como estão funcionando e esta é uma importante tarefa da auditoria interna, onde demonstra para os gestores e diretores da 
companhia, um conjunto de processos, que funcionam mediante o acompanhamento, e que visem a corrigir algum equívoco. A auditoria interna tem como meta adicionar valor às atividades organizacionais, pois auxilia no alcance de objetivos organizacionais, mediante uma abordagem sistemática, onde realiza a melhoria da eficácia de processos, melhora no gerenciamento, controle e da governança corporativa.

Levando em conta que o objetivo da empresa é gerar lucro e que o mesmo é obtido através da boa administração, a auditoria é uma ferramenta essencial para o controle das empresas, onde tem como foco a conferência de operações e relatórios, podendo desvendar possíveis fraudes e falhas nos procedimentos empresariais e também avaliar procedimentos internos, verificando se existem ocorrências que necessitam ser modificadas, visando o melhoramento e progresso da instituição. A auditoria está deixando de ser uma atividade somente investigadora e certificadora para ser mais participativa, avaliando o desempenho empresarial e gestão estratégica de negócios, apontando as falhas e seus reflexos, além de impor medidas para resolução de problemas. A auditoria interna, especificamente, é o acompanhamento e conferência minuciosa de tudo o que ocorre na empresa, englobando todos os setores: administrativo, contábil e operacional, ao contrário da auditoria externa, que está limitada aos demonstrativos contábeis. A auditoria visa a autenticidade dos relatórios e maior segurança para as empresas, sócios, acionistas e terceiros, o que é de vital relevância para qualquer entidade, além de servir como ferramenta de autocontrole para as empresas (MONARETTO, 2008).

A auditoria interna passou a ser um instrumento amplo de controle para os administradores, para verificação sistemática da eficácia e eficiência das atividades operacionais e identificação de todos os processos internos e políticas definidas pela companhia, a fim de evitar situações que propiciem fraudes, desfalques e subornos, através de testes regulares nos controles internos específicos de cada organização. A auditoria interna constitui o conjunto de procedimentos que tem por objetivo examinar a integridade, adequação e eficácia dos controles internos e das informações físicas contábeis, financeiras e operacionais da entidade, é uma atividade de avaliação independente dentro da empresa como um serviço prestado à administração. O objetivo da auditoria interna é verificar se os procedimentos internos estão sendo seguidos, auxiliando todos os membros da administração no desempenho efetivo de suas funções e responsabilidades, fornecendo-lhes análises, apreciações, recomendações e comentários pertinentes às atividades examinadas. A auditoria interna deve assessorar a administração da entidade no trabalho de prevenção de fraudes e erros, obrigando-se a informá-la, sempre por escrito, de maneira reservada, sobre quaisquer indícios ou configurações de irregularidades detectadas no decorrer de seu trabalho (PRADO, 2010).

Foi constatado que através da necessidade, a aplicabilidade de uma auditoria eficaz e controles internos eficientes e organizados podem ser fundamentais para a redução de fraudes empresariais, logo, a falta ou fraqueza desses controles é o que facilita a sua ocorrência. A auditoria é uma ferramenta essencial para o controle das empresas, onde tem como foco a conferência de operações e relatórios, podendo desvendar possíveis fraudes e falhas nos procedimentos empresariais e também avaliar procedimentos internos, verificando se existem ocorrências que necessitam ser modificadas, visando a melhoria da eficácia de processos, melhora no gerenciamento, controle e da governança corporativa, trazendo o progresso da 
instituição. Portanto, através do debate realizado entre os pesquisadores, entende-se que a auditoria não é apenas uma técnica onde verifica e testa os controles internos e confere, verifica, e avalia documentos e demonstrações para obter informações, é também uma ferramenta que auxilia os administradores na tomada de decisão, atingir seus objetivos, a reduzir custos, fraudes e distorções e a se destacar no meio competitivo.

\section{CONCLUSÕES}

Não se pode afirmar que a auditoria torna impossível a existência de erros e fraudes no controle do patrimônio e suas variações, porém com todo um aparato ela reduz essa possibilidade. Com a auditoria interna, além de reduzir essas distorções traz também vantagens tanto para a administração, investidores, fiscos, como também para a sociedade como um todo. Essa ferramenta oferece vantagens como: fiscalizar a eficiência dos controles internos e apontar as falhas, sugerir correção dos registros contábeis, dificultar desvios de bens patrimoniais, contribuir para obtenção de melhores informações sobre a real situação econômica, patrimonial e financeira da organização, contribuir para a observância das leis fiscais, dar credibilidade às demonstrações contábeis e assegurar a veracidade das informações. A auditoria não conduz o administrador que direção deve seguir, pois a ela cabe a função de organizar os relatórios e pareceres que possuem caráter opinativo e não obrigatório. A auditoria é uma ferramenta de apoio e assessoramento à gestão, em que se mostram os melhores caminhos, as boas práticas e os melhores controles, sem impor regras de conduta e novos procedimentos, mas isso serão decisões que cabem somente ao próprio administrador seguir ou não. Portanto, conclui-se que não há coerência dizer que a auditoria é um problema ou um custo, ao contrário, esse paradigma perverso e incoerente deve ser suplantado em face da necessidade da administração de verificar, analisar, controlar e prestar contas aos usuários internos e externos, ou seja, a auditoria aponta soluções para os problemas. O controle interno serve como o alicerce, como suporte operacional para auditoria interna, na redução de fraudes e distorções, além de adicionar valor à organização, na sua ausência os administradores não têm noção do posicionamento no mercado.

\section{REFERÊNCIAS}

BORDIN, P.; SARAIVA, C. J.. O controle interno como ferramenta fundamental para a fidedignidade das informações contábeis. Revista Eletrônica de Contabilidade, Santa Catarina, v.2, n.3, 2005. DOI: http://dx.doi.org/10.5902/198109466224

CFC. Conselho Federal de Contabilidade. Normas brasileiras de contabilidade: auditoria interna: NBC TI 01 e NBC PI 01. Brasília: CFC, 2012.

CORDEIRO, C. M. R.. Perícia Contábil. Curitiba: IESDE Brasil, 2011.

GOMES, E. D.; ARAÚJO, A. F.; BARBOZA, R. J.. Auditoria: alguns aspectos a respeito de sua origem. Revistas Eletrônicas do Grupo FAEF, v.7, n.13, 2009.

HAMES, G.. A importância da auditoria interna no processo decisório das organizações: uma revisão de literatura. Florianópolis: UFSC, 2004.

LIMA, H. M. A.; MELO, F. A. O.; REIS, P. N. C.; LIMA, C. C. S.; OLIVEIRA, V. M. S.. Controle interno como ferramenta essencial contra erros e fraudes dentro das organizações. In: SIMPÓSIO DE EXCELÊNCIA EM GESTÃO E TECNOLOGIA, 9. Anais. SEGeT, 2012.

LINS, L. S.. Auditoria: uma abordagem prática com ênfase na auditoria externa. 2 ed. São Paulo: Atlas, 2012.

MARÇOLA, C.. Auditoria interna como instrumento de controle social na administração pública. Revista do Serviço Público, Brasília, v.62, n.1, 2011.

MONARETTO, C.. Auditoria interna em concessionária de veículos, através da contabilidade integrada. Curitiba: Universidade Tecnológica Federal do Paraná, 2008. 
OLIVEIRA, S. P.. O controle interno como suporte operacional da auditoria interna para redução de fraudes. Cuiabá: AJES, 2009.

PEREIRA, J. S. R.. A auditoria e a gestão do risco empresarial. Tomar: Instituto Politécnico de Tomar, 2012.

PINHEIRO, C. G. A.. Acrescentar valor à organização com a auditoria interna. Porto: ISCAP, 2013.

PINHEIRO, G. J.; CUNHA, L. R. S.. A importância da auditoria na detecção de fraudes. Contab. Vista \& Rev., Belo Horizonte, v.14, n.1, 2003.

PINHO, R. C. S.. Fundamentos de auditoria: auditoria contábil: outras aplicações de auditoria. São Paulo: Atlas, 2007.

PRADO, A. P.. Auditoria interna e a sua importância no processo decisório das empresas. São Luís: Universidade
Candido Mendes, 2010

ROSÁRIO, E. D.. Relação entre auditores independentes e auditados: um estudo de caso em uma entidade fechada de previdência complementar. Florianópolis: 2010.

SANTOS, E. S.; GONÇALVES, C. R. M.; ALMEIDA, A. S.. A importância da auditoria contábil nas empresas e entidades do terceiro setor. Revista Eletrônica FANESE, v.3, n.1, 2014.

SILVA, A. C. R.. Metodologia da pesquisa aplicada à contabilidade: orientações de estudos, projetos, artigos, relatórios, monografias, dissertações, teses. 3 ed. São Paulo: Atlas, 2010

TRISCIUZZI, C. R. F.. A Auditoria Interna como ferramenta de melhoria dos controles internos de uma organização: estudo de caso em uma empresa do segmento industrial do Rio de Janeiro. Rio de Janeiro: Universidade do Estado do Rio de Janeiro, 2009.

A CBPC - Companhia Brasileira de Produção Científica (CNPJ: 11.221.422/0001-03) detém os direitos materiais desta publicação. Os direitos referem-se à publicação do trabalho em qualquer parte do mundo, incluindo os direitos às renovações, expansões e disseminações da contribuição, bem como outros direitos subsidiários. Todos os trabalhos publicados eletronicamente poderão posteriormente ser publicados em coletâneas impressas sob coordenação da Sustenere Publishing, da Companhia Brasileira de Produção Científica e seus parceiros autorizados. Os (as) autores (as) preservam os direitos autorais, mas não têm permissão para a publicação da contribuição em outro meio, impresso ou digital, em português ou em tradução. 